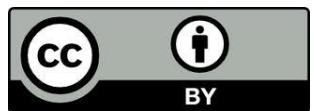

\title{
IGREJA HOLINESS DE LONDRINA-PR: UMA FACE DA RELIGIOSIDADE NIPÔNICA
}

\author{
Holiness Church in Londrina-PR: a face of Japanese's religiosity \\ Ana Cláudia Rodrigues de Oliveira \\ Universidade Estadual de Londrina \\ Mestranda em Ciências Sociais pela Universidade Estadual de Londrina \\ , vinculada ao grupo de pesquisa "História, Sociedade e Religiões" \\ CNPQ UEL, ao LERR - Laboratório de Estudos \\ sobre Religiões e Religiosidades e ao Programa OBEDUC - CAPES/Ciências Sociais UEL \\ anaclaudia-oliveir@hotmail.com \\ José Wilson Assis Neves Junior \\ Universidade Estadual de Londrina \\ Mestre em Ciências Sociais pela Universidade Estadual de Londrina, \\ vinculado ao grupo de pesquisa "História, Sociedade \\ e Religiões”, ao LERR - Laboratório de Estudos sobre Religiões e Religiosidades \\ nevesjr1991@gmail.com \\ Fábio Lanza \\ Universidade Estadual de Londrina \\ Doutor em Ciências Sociais (PUC-SP), professor adjunto do Departamento e do Programa \\ de Pós-Graduação em Ciências Sociais da UEL - Londrina/PR \\ Supervisor do PIBID e pesquisador do Programa OBEDUC - CAPES/Ciências Sociais UEL. \\ lanza1975@gmail.com
}

RESUMO: Os processos de imigração compuseram o contexto regional do Norte do Paraná ao longo do século XX, entre os diferentes fluxos migratórios para a formação da cidade de Londrina, destacamos a população nipônica. A partir da observação participante, realizada na sede da Igreja Holiness de Londrina, foi possível perceber que apesar de estar presente na cidade há aproximadamente 76 anos ela continua sendo predominantemente frequentada por membros de descendência japonesa, tendo dentre eles imigrantes idosos que não fazem uso da língua portuguesa. Foram necessárias contribuições advindas da Sociologia das Religiões e da Escola de Chicago no que tange o processo de observação participante, bem como, uma pesquisa bibliográfica sobre a temática. Este trabalho apresenta as características centrais da instituição londrinense e da prática religiosa de seus membros, foi possível perceber o papel histórico desempenhado pela instituição e sua importância em termos da socialização dos descendentes nipobrasileiros de Londrina.

Palavras chave: Religiosidade nipo-brasileira; Movimento Pentecostal; Movimentos Migratórios.

ABSTRACT: The immigration processes has composed the regional context in the North of Paraná during the XX's century, between different migratory fluxes that were responsible for forming Londrina's urban space, we accentuate the Japanese population. By the participant observation, performed in the Londrina's Holiness Church, were possible realize that in spite of being in the city for approximately 76 years the Church continues to be predominantly frequented by Japanese descendants, having between them old immigrants that do not speak Portuguese. Were necessary the contributions from Sociology of Religions and the participant observation methods from the Chicago School of sociology, as well as a literature about the theme. This work shows the central features of the institution in Londrina and the religious practice of his members, were possible realize the historical role of the institution and his importance to the socialization of the Japanese-Brazilians descendants in Londrina.

Keywords: Japanese-Brazilians religiousness; Pentecostal Movement; Migration’s Movement. 


\section{Introdução}

Ao empreender uma análise a respeito da nova onda migratória mundial, com destaque para o atual movimento Haiti/Brasil, Patarra e Fernandes (2001) abordam uma problemática inerente ao rótulo e/ou mito concedido ao Brasil como "país da imigração". Por meio de uma perspectiva histórica de análise dos processos migratórios para terras tupiniquins os autores ressaltam a necessidade de observar o misto de práticas assimilativas e discriminatórias que podem ser atribuídas aos processos de acordo com o contexto no qual se encontram inseridos.

É ressaltada, desta forma, a importância de atentar-se as especificidades das distintas inserções de grupos migrantes de acordo com os espaços sócio/político/econômico/culturais aos quais passam a compor. Dentro desta perspectiva André (2011) chama a atenção para os limites impostos aos imigrantes japoneses que chegaram ao Brasil no século XX, sendo necessário que os mesmos atendessem aos condicionantes, pré-determinados e estabelecidos por contratos, para que fossem recepcionados pelo mercado de trabalho nacional, sendo eles, estar: em gozo de boa saúde, integrado à família e apto a exercer suas atribuições nas fazendas.

Percebe-se, assim, a relevância de empreender estudos a respeitos das distintas especificidades que decorreram dos múltiplos processos migratórios ocorridos no território brasileiro, dado especial enfoque a forma como as culturas dos imigrantes foram aceitas, assimiladas, ou mesmo reprimidas, de acordo com os contextos onde foram inseridas.

Este artigo foi elaborado a partir da expansão da análise dos resultados obtidos do trabalho de observação de campo realizado na instituição religiosa Igreja Evangélica Holiness de Londrina em 2013, vinculada ao Laboratório de Estudos sobre Religiões e Religiosidades LERR da Universidade Estadual de Londrina (UEL-PR).

A seleção desta instituição para a observação de campo ocorreu em função da relevância das questões vinculadas à presença dos imigrantes japoneses na cidade de Londrina e das religiosidades orientais que refletem tal presença, sobre as quais pouco foi produzido. A Holiness foi selecionada por representar de modo especial a dinâmica cultural do espaço religioso na modernidade combinando diferentes elementos étnicos religiosos e culturais. 
A Igreja Evangélica Holiness de Londrina compõe - ao lado da Sociedade Missionária Oriental, Igreja Local, Igreja Gnóstica Oriental, Templo Budista Hompoji, Templo Budista Honpa Hongwanji e Templo Budista Soka Gakkai - o quadro mais expressivo de religiosidades orientais na cidade.

A pesquisa exposta partiu, assim, da perspectiva de empreender uma observação participativa da instituição religiosa de maneira a compreender o modo como o espaço por ela disponibilizado permitiu, e ainda permite, um constante processo de hibridização cultural que, por meio de uma continua (re)significação da realidade social, permite tanto a assimilação das diretrizes ocidentais que são impostas aos nipo-descendentes quanto a continuidade de tradições culturais japonesas, e mesmo a apropriação de novas formações culturais contemporâneas do Japão - ressaltando ainda o papel desempenhado pela instituição religiosa no que tange a difusão da cultura nipônica para os demais grupos culturais que compõem a multiplicidade social da região metropolitana de Londrina-PR.

\section{A origem da Igreja Holiness e sua chegada ao Brasil}

A pesquisa de campo e a bibliográfica permitiram a constatação da inexistência de produções acadêmicas engajadas em estudos sobre religiosidades que abordassem de modo específico o caso da Igreja Evangélica Holiness, ou que trabalhassem de alguma forma com o tema de sua origem e história, bem como sua instalação no país.

As fontes disponíveis para a investigação sobre o surgimento e a história desta instituição religiosa foram os sites institucionais de sedes da própria Igreja Evangélica Holiness em várias cidades brasileiras.

De acordo com informações históricas disponibilizadas em tais $\operatorname{sites}^{1}$ oficiais da Igreja Holiness no Brasil, de Curitiba e de Londrina verificou-se a existência de uma ampla relação entre a história do surgimento da instituição e a história do Movimento Pentecostal norte-americano e sua expansão no início do século XX.

\footnotetext{
${ }^{1}$ Web sites que disponibilizam a história da Igreja Holiness:

Igreja Evangélica Holiness do Brasil: http://www.holiness.org.br/holiness/ - acesso em 09/08/2014 as $21 \mathrm{hrs} 33 \mathrm{~min}$.

Igreja Evangélica Holiness de Curitiba: http://www.holinesscwb.com/ - acesso em 09/08/2014 $21 \mathrm{hrs} 47 \mathrm{~min}$.

Igreja Evangélica Holiness de Londrina: http://holinesslondrina.wordpress.com/ - acesso em 09/08/2014 $22 \mathrm{hrs} 03 \mathrm{~min}$.
} 
Os dados sobre o processo histórico e social coletados na pesquisa eletrônica citada indicam que no final do século XIX o pastor Juji Nakada liderava, ao lado de sua esposa, uma das sedes da Igreja Metodista no Japão, porém desejava abandonar seu ministério por estar desmotivado com o que para ele seria um baixo índice de japoneses evangelizados (cerca de $20 \%$ da população ${ }^{2}$ ).

Antes de desistir de sua liderança ele viajou a pedido de sua esposa até o Instituto Bíblico Moody ${ }^{3}$ localizado na cidade de Chicago, em Illinois (Estados Unidos), onde teve contato com pressupostos teológicos do Movimento Pentecostal e conheceu o casal Charles e Lettie Cowman, ambos missionários da Igreja Metodista da Graça.

O pastor Juji retornou ao Japão onde iniciou a fundação da Sociedade Missionária Oriental que posteriormente, com a visita e apoio do casal de missionários que havia conhecido no Instituto, se tornou a primeira Igreja Holiness do Japão (fundada em 1901).

A palavra inglesa holiness, escolhida para o nome desta instituição, corresponde à palavra "santidade" na língua portuguesa e marca a importância da "doutrina da santificação" que juntamente com elementos da tradição wesleyana ${ }^{4}$ compõe o corpo teológico dessa instituição religiosa.

A Igreja Holiness se identifica, portanto, como uma igreja evangélica de matriz pentecostal, com origens justamente no contato entre a Igreja Metodista (que por sua vez tem raízes no protestantismo histórico) e o Movimento Pentecostal NorteAmericano, que se relaciona a ideia de "avivamento espiritual" por meio do contato com elementos sobrenaturais do credo protestante, como, por exemplo, experiências de batismo no Espírito Santo.

A primeira Igreja Holiness do Brasil foi instituída em 1925 na cidade de Registro em São Paulo, ou seja, apenas 24 anos após sua fundação no Japão, fato que se relaciona com a chegada de imigrantes japoneses no país. O número de IEHs (Igreja Evangélica Holiness) foi se ampliando conforme crescia o número de imigrantes de

\footnotetext{
${ }^{2}$ Fonte eletrônica: idem.

${ }^{3}$ O Moody Bible Institute localiza-se em Chicago e continua ativo até a atualidade. Para maiores informações visite o endereço eletrônico do Instituto: http://www.moody.edu/

4 Preceitos teológicos elaborados por John Wesley, teólogo britânico que após romper com o anglicanismo foi o líder religioso do movimento metodista, que posteriormente culminou na fundação da Igreja Metodista.
} 
oriundos do Japão. Atualmente, segundo o site nacional da própria instituição, existem 46 sedes da Igreja Evangélica Holiness no Brasil.

\section{A Igreja Holiness de Londrina}

Conforme apresenta André (2009) os processos de migração Japão-Brasil são historicamente demarcados pela existência de distonâncias no que tange à receptividade por parte do governo brasileiro, assim como sua própria população - note-se que as décadas de 1930 e 40 foram caracterizadas por um forte sentimento antinipônico, disseminado por grupos nativistas e futuramente aderido pelo regime totalitário do Estado Novo (1937-1945). Segundo o pesquisador uma série de medidas aprovadas pelo Estado Novo foram prejudiciais não somente para o próprio fluxo migratório como também para a manutenção da cultura dos diferentes povos imigrantes, entre eles os japoneses, dentro deste contexto se encontra a proibição, aprovada em 1939, de utilização de qualquer língua estrangeira nos espaços públicos ou privados.

Em contrapartida no período pós-guerras os meios de comunicação social, entre eles os paranaenses, se incumbiram em disseminar uma imagem altamente positiva do imigrante japonês, apresentado como detentor de uma ampla capacidade para o desenvolvimento econômico (ANDRÉ, 2009).

A partir dos dados coletados no campo de observação a instituição religiosa Holiness localiza-se na Rua Terezina na Vila Shima Bokuro, bairro situado na região central de Londrina - Paraná. A igreja foi fundada 13 anos após a chegada da Igreja Holiness do Brasil (1938), ou seja, está presente na cidade há 76.

A história oficial da cidade de Londrina buscou ao longo das décadas do século XX fomentar a valorização da cultura inglesa vinculada aos primeiros especuladores imobiliários e responsáveis pela colonização tardia a partir da década de 1930. Na atualidade, graças a ampla produção vinculada as novas abordagens da História e Ciências Sociais, o mito do pioneiro fundador foi contraposto pelo reconhecimento de diferentes grupos imigrantes de trabalhadores à cidade. Como destaque, podemos citar 
as obras vinculadas aos pesquisadores do Laboratório de Estudos Afro-brasileiros da $\mathrm{UEL}^{5}$.

Para nosso recorte, que tange a imigração nipônica, é considerável o período de tempo em que a Igreja Holiness se consolidou na cidade, no entanto, foi possível perceber que continua sendo frequentada predominantemente por imigrantes japoneses da cidade e seus descendentes.

Ponto relevante para esta pesquisa reside na constatação do espaço urbano no qual a Igreja Holiness se encontra. Conforme apresenta Rodrigues (2016), os movimentos migratórios em centros urbanos norte-americanos (New York, New Jersey, Newark, entre outros) tendem a gerar espaços urbanos de concentrações étnicas (Little Italy, Little Portugal, China Town, entre outros), fenômeno que possibilita a construção de um espaço fortalecido de preservação, e mesmo difusão, da cultura nacional dos migrantes, assim como de sua religiosidade. Ressalta-se ainda que dentro desta realidade o autor chama a atenção para a tendência observada do processo de importação de instituições religiosas nacionais que acompanham seus movimentos migratórios. Neste ponto Rodrigues (2016) dirige especial atenção a forma como a Igreja Universal do Reino de Deus acompanha os movimentos migratórios de brasileiros para os diferentes países economicamente hegemônicos (EUA, Japão e países europeus).

No que se refere ao caso particular da Igreja Holiness, na cidade de Londrina, algumas especificidades devem ser levadas em considerações para que não ocorra o risco de ingenuamente atribuir a sua localização a classificação enquanto espaço urbano de concentração étnica.

Assim, importante se faz notar que apesar da instituição evangélica nipobrasileira estar situada a aproximadamente cem metros do Templo Budista Honpa Hongwanji, o espaço urbano que caracteriza seus arredores não se constituí pela ocupação predominante por descentes japoneses. Mas sim como um espaço central de grande ênfase de comércio, no qual coexiste a multiplicidade cultural londrinense. Salienta-se, desta forma, que a ocupação religiosa dos migrantes japoneses no espaço urbano londrinense não segue as mesmas diretrizes da realidade dos centros urbanos norte-americanos identificada por Rodrigues (2016).

\footnotetext{
${ }^{5}$ Disponíveis em: http://www.uel.br/projetos/leafro/pages/publicacoes-da-equipe-leafro.php, acessado em 07/10/2016.
} 
Esta especificidade da realidade sócio espacial londrinense gera uma implicação subsequente, compreender que não é um espaço restrito de predominância populacional japonesa, apesar de estar associado a duas instituições religiosas nipônicas. No entanto, consequentemente, as instituições religiosas e as associações étnicas se constituíram no espaço por excelência da socialização e preservação da cultura nacional de origem.

Ao refletir sobre o processo de nossa pesquisa de campo, faremos alguns destaques descritivos a partir dos cultos dominicais. Fomos recebidos por alguns membros da igreja que nos apresentaram alguns aspectos da história da igreja na cidade e nos mostraram seu espaço físico.

A primeira característica física, externa que merece destaque, do templo da Igreja Evangélica Holiness de Londrina é o nome da Igreja em escrita japonesa gravado na fachada de granito logo na entrada do espaço físico da instituição. Em seguida, no hall de entrada está afixado um memorial informando sobre a história do surgimento da Holiness na cidade e sua relação com o processo de imigração.

Ao lado da entrada encontra-se uma grande mesa com várias versões de bíblias que estavam à venda. A maioria delas escrita na versão japonesa, outras em língua portuguesa. No mesmo local onde eram vendidas as bíblias estavam dispostos alguns produtos naturais, como, por exemplo, ervas para chás curativos.

Era fácil nos identificar como visitantes e pesquisadores. Contabilizamos entre as pessoas presentes que apenas seis pessoas que não possuíam características fenotípicas japonesas, enquanto cerca de 30 pessoas possuíam eram nipo-brasileiros. A grande maioria dos fiéis frequentadores dessa denominação é de origem japonesa, os demais são maridos ou esposas de outros membros japoneses.

No templo notamos vários aspectos diferentes dos religiosos brasileiros, como as faixas com escritos japoneses decorando o altar. Nele há também um estúdio de som e tradução, as traduções simultâneas dos cultos são apresentadas no local e transmitidas, online na internet, na língua japonesa. Segundo o depoimento oral do pastor, essa tradução simultânea é necessária por conta da existência dos membros idosos que não utilizam a língua portuguesa.

Nos fundos da Igreja há outras instalações como salas de Escola Dominical para crianças, jovens e adultos, salão de eventos, sala de leitura (com sofás, livros e gibis) e quadra de esportes. Notamos em uma das salas um quadro com anotações dos horários 
de jogos de várias modalidades esportivas. Os jovens da Holiness marcam semanalmente campeonatos de várias modalidades de jogos como tênis, futebol e basquete.

Além da Escola Dominical para as crianças, existe um tipo de organização voltada para o público adolescente e juvenil, é o "Encontro de Jovens", que de acordo com os membros está sempre muito cheio, há também o "Encontro de Mulheres" e o Ministério Louvarte (Ministério de Louvor e Artes), que realiza esporadicamente, excursões e temporadas que incluem os jovens e crianças para atividades recreativas. $\mathrm{O}$ Louvarte também organiza apresentações para o Festival Matsuri de Londrina.

Observando as fotos ${ }^{6}$ das atividades religiosas percebemos que ocorrem na Igreja algumas celebrações com junção da temática oriental, como Café da Manhã das Mães, com comidas japonesas, danças e origamis na decoração.

Outro evento interessante foi a Festa Oriental dos Jovens, na qual os membros se vestiram com fantasias de personagens ou objetos próprios da cultura oriental. Roupas típicas de artes marciais, mangás, personagens de quadrinhos e desenhos japoneses, quimonos entre outras vestimentas orientais muito coloridas chamam atenção nas fotos.

$\mathrm{Na}$ área do bebedouro da Igreja existe um suporte afixado na parede, uma espécie de porta-copos de grande proporção onde são pendurados copos com os nomes dos membros frequentadores da Igreja. Copos descartáveis são reutilizados durante os cultos para reduzir o volume de lixo produzido. Ao lado do bebedouro ficam copos para visitantes com adesivos e pincel atômico para que também façam marcações em seus copos.

Os cultos dominicais são realizados às $10 \mathrm{~h} 00$ da manhã e as $18 \mathrm{~h} 30$ da noite e em termos de organização são muito parecidos com os cultos nas outras igrejas evangélicas pentecostais: conta com o momento de louvor, apresentação de visitantes, e o momento da mensagem bíblica. No entanto notamos algumas características peculiares que são dados da realidade religiosa, como por exemplo, o grupo que promoveu o louvor do dia de nossa visita era composto por jovens entre 14 e 18 anos e as músicas eram de cunho tradicional evangélico.

\footnotetext{
${ }^{6}$ Disponíveis no perfil virtual da instituição: https://www.facebook.com/HolinessLondrina?fref=ts
} 


\section{Da observação participativa}

A observação de campo realizada na Igreja Evangélica Holiness de Londrina ocorreu no ano de 2013, ano no qual o pastor Roberto Shinze Yahiro liderava a Holiness juntamente com sua esposa, a pastora Dilma Higa Yahiro.

As particularidades do objeto tratado nesta pesquisa implicaram na escolha preferencial dos métodos de pesquisa qualitativa e sob a perspectiva teórica da Escola de Chicago em seus trabalhos relacionados à Antropologia Urbana e as consequências dos processos de urbanização e migração das cidades norte americanas do início do século passado.

Desta forma, devemos considerar a cidade como "o habitat natural do homem civilizado. Por essa razão ela é uma área cultural caracterizada pelo seu próprio tipo cultural peculiar" (PARK, 1979, p.27).

Tal proposição determina que o caso aqui estudado tenha de ser considerado como objeto único de pesquisa, determinado por contextos históricos, sociais, políticos, culturais e geográficos que culminaram na formação do mesmo, a existência de casos semelhantes pode ser considerada válida, porém, com a distinção devida das particularidades cabíveis a cada um dos casos.

Devemos ainda apresentar as contribuições de Joseph (2005), segundo o qual as sociedades urbanas tendem a gerar uma forma ou outra de pluralidade de línguas ou culturas e que as cidades e, sobretudo, as grandes metrópoles são por excelência os lugares das minorias, salientando ainda que:

O espaço da cidade, visto pela perspectiva do migrante, se estende e se retrai, de acordo com suas atividades, posição social ou momento de sua migração. A cidade deixa perceber, assim, uma distribuição não apenas de nacionalidades, mas também de posições de inserção ou de etapas do percurso migratório (JOSEPH, 2005, p. 105).

Seguindo esta linha de pensamento devemos considerar a Igreja Holiness como instalada em um bairro de maioria quase absoluta de descendentes nipônicos da cidade de Londrina - cujo próprio nome, Vila Shima Bokuro, nos remete a cultura japonesa.

Ademais devemos considerar, a partir dos apontamentos de Park (1979), a influência dos gostos e interesses pessoais no processo de segregação e classificação populacional nas grandes cidades, mostrando ainda que os métodos etnográficos 
provindos da Antropologia podem ser aplicados no ambiente urbano das grandes metrópoles, possibilitando uma maior compreensão dos costumes, crenças, práticas sociais e concepções gerais de vida dos habitantes de um determinado grupo social

Para compreender as relações estabelecidas, em meio à comunidade da Igreja Holiness, é imprescindível a assimilação do método de observação participativa, tendo em vista que, segundo o interacionismo simbólico, as significações sociais são produtos da interação entre agentes

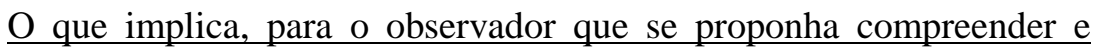
analisar essas significações, a adoção de uma postura metodológica que autorize essa análise. O pesquisador só pode ter acesso a esses fenômenos particulares que são as produções sociais significantes dos agentes quando participa, também como agente, do mundo que propõe a estudar (COULON, 1995, p. 19).

Deve-se, também, deixar claro que o papel exercido nesta pesquisa no que tange ao método da observação participativa ocorreu por um período curto e apesar de estar em contato com os membros do grupo, não toma parte de suas atividades como um membro em si.

\section{Identidade imigrante e socialização religiosa}

O ponto central tomado para esta análise é a relação entre a Igreja Holiness e a imigração japonesa de Londrina, que nos permite pensar nas funções que tal instituição assume e qual sua relevância para esses indivíduos que dela participam.

Os próprios membros demonstraram o desejo de estimular o olhar dos "visitantes pesquisadores" para os detalhes presentes naquele espaço físico que expressam características da cultura japonesa. O espaço de sociabilidade criado na Igreja Holiness de Londrina permite aos membros práticas de afirmação de suas identidades socioculturais e preservação de aspectos oriundos da descendência nipónica.

Nessa perspectiva, podemos compreender o referencial proposto por Peter Berger quando formulou o conceito de legitimação religiosa, pois nas situações marginais relatadas pelo autor, os indivíduos buscam a religião como uma forma de se apoiarem diante de alguma condição de risco, de ameaças a estabilidade ou sociabilidade. Desta maneira "a legitimação religiosa pretende relacionar a realidade 
humanamente definida com a realidade última, universal e sagrada" (BERGER, 1985, p. 48)

Podemos identificar o processo da imigração japonesa na cidade, que completou recentemente 105 anos, como uma das situações marginais descritas pelo autor e, portanto, a valorização do meio religioso como forma de proteção dos imigrantes.

Os imigrantes japoneses foram submetidos à imposição da assimilação de culturas hegemônicas do país, e passaram por variadas dificuldades, estranhamentos e adaptações forçadas.

Quanto ao fenômeno da assimilação devemos considerar os apontamentos de William Thomas - expostos por Coullon (1995) - segundo o qual a assimilação tem por exigência a construção de uma memória comum entre o nativo e o imigrante, chegando a recomendar a familiarização do nativo para com a cultura do imigrante.

A partir desta contribuição notamos o importante papel exercido pelo Festival Matsuri de Londrina ${ }^{7}$ no processo de familiarização da cultura nipônica por parte dos demais indivíduos que compõe a pluralidade social brasileira, possibilitando, assim, a valorização e influência da cultura japonesa na formação da identidade londrinense.

Devemos considerar também a notável hibridização cultural (nipo-brasileira) no ambiente da própria Igreja - a disponibilização da tradução simultânea das falas em português para o japonês; a diversidade de pratos típicos, orientais e ocidentais, nas festas da comunidade; a realização de eventos característicos tanto da raiz oriental como da ocidental; a valorização da utilização de ervas medicinais (típica da cultura oriental) em um meio evangélico ocidental.

A Igreja Holiness pode ser tomada, portanto, como um ambiente que possibilita, não só a assimilação da cultura ocidental, como também, a valorização e a continuidade da cultura japonesa, um processo de hibridização cultural, não apenas típico, mas, também, necessário para os movimentos de imigração.

Dentro desta perspectiva deve ser ressaltado que a "prática religiosa é sempre um ato parcialmente criativo, representando uma imparável atividade imaginativa, dirigida à construção de imagens sensatas de uma realidade intrinsecamente instável e mutável” (ROMIZI, 2016, p.3). Tal percepção acerca do papel social desempenhado pela religiosidade, permite compreender a forma como um espaço religioso previamente

\footnotetext{
${ }^{7}$ Festival anual, que ocorre no mês de Setembro, aberto à toda sociedade local e regional.
} 
híbrido, em relação ao movimento migratório, potencializa o processo de tradução cultural de cosmovisões ocidentais no espaço ocupado pelos imigrantes japoneses, realizando uma continua (re)significação da realidade de forma a adequar elementos básicos da cultura nipônica as novas condições sociais que são impostas aos seus membros.

Seguindo a perspectiva de Robert Park (1979) entendemos o papel fundamental da associação - neste caso, religiosa - de imigrantes que se mantém até a atualidade como um espaço predominantemente japonês, que, contudo, não deixa de transparecer a absorção das diferentes culturas, brasileiras e ocidentais.

A investigação permitiu ampliar estudos sobre o processo de globalização religiosa contemporânea, como parte conclusiva temos que reconhecer que uma perspectiva cristã protestante que se instalou no Japão, lá produziu seu proselitismo e conquistou adeptos. Posteriormente, parte dessa população japonesa cristã protestante engajou-se no movimento migratório para o Brasil e ao compor a colonização na região Norte do Paraná consolidou uma instituição religiosa que se preserva e ao mesmo tempo se atualiza na sociedade londrinense.

É possível afirmar que os imigrantes japoneses em Londrina PR foram inseridos em um ambiente totalmente alheio aos seus costumes e tradições - salientando a possibilidade de resistências sociais, hostilidades, ao processo de imigração por parte dos "nativos" da sociedade. Estes indivíduos encontraram na associação de imigrantes um meio no qual podem se constituir como grupo, assimilar a cultura da nova sociedade na qual passaram a compor, ao mesmo tempo em que preservam ou modificam valores sociais, religiosos e culturais trazidos pelos imigrantes japoneses no Brasil e em Londrina PR.

\section{Considerações Finais}

A partir do método da observação participativa encontrou-se a possibilidade de analisar a realidade social em meio ao ambiente de socialização da Igreja Holiness salientando a superficialidade de assimilação da vivência e das visões de mundo dos membros da comunidade por parte dos pesquisadores, dado o curto período de tempo 
empreendido na pesquisa e a opção pelo posicionamento observador participante no processo.

Foi possível, contudo, delimitar o papel exercido pela comunidade religiosa, no que diz respeito ao processo de hibridização cultural, que possibilitam a assimilação das diferentes culturas, tanto por parte dos imigrantes japoneses como pelos diferentes grupos sociais que constituem a pluralidade cultural da sociedade londrinense, favorecendo a produção de uma identidade londrinense múltipla e rica nas diferentes contribuições culturais decorrentes do processo de imigração.

O espaço de sociabilidade proporcionado pela fundação da Holiness de Londrina permitiu a legitimação da cultura e religiosidade, bem como, fomentou a solidariedade social entre seus membros.

A chegada da imigração japonesa pode ser entendida como um momento de "situação marginal" para os imigrantes e seus descendentes por se tratar de um deslocamento que implica dificuldades de adaptação à nova cidade, que possui uma cultura diferente, hábitos, tradições idiomas.

Essas dificuldades caracterizaram uma experiência de alteridade e instabilidade para esses indivíduos. A eficácia do sagrado, mencionada por Berger (1985), pode ser percebida no caso investigado, pois a instituição religiosa serviu como mediadora para legitimar sua cultura e suas crenças e criar um meio de inserção social para tais pessoas.

Como hipótese para futuras pesquisas, poderíamos fomentar que as denominações religiosas nipo-brasileiras como a Sociedade Missionária Oriental, Igreja Local, Igreja Gnóstica Oriental, Templo Budista Hompoji, Templo Budista Honganji e Templo Budista Hongwanjio desempenharam um papel fundamental no processo de socialização desses imigrantes japoneses em Londrina PR.

\section{.Referenciais}

ANDRÉ. Richard G. A Imigração Japonesa no Brasil: História e Memória, Fronteiras e Interpretações. Revista On-line História e-História, Campinas, 18 de agosto de 2009. Disponível no endereço eletrônico:

$<$ http://www.historiaehistoria.com.br/indice.cfm?tb=alunos\&startrow=346> (acessado em 02/08/2016). 
ANDRÉ. Richard G. Religião e Silêncio: representações e práticas mortuárias entre nikkeis em Assaí por meio de túmulos (1932-1950). 2011. Tese (Doutorado) apresentada à Universidade Estadual Paulista (UNESP-Assis).

BERGER, P. L. O dossel sagrado: elementos para uma teoria sociológica da religião. São Paulo: Editora Paulus, 1985.

COUlON, A. A Escola de Chicago. São Paulo: Editora Papirus, 1995.

JOSEPH, I. A respeito do bom uso da Escola de Chicago. In: VALADARES, L. (org).

A Escola de Chicago. Rio de Janeiro: IUPERJ/UFMG, 2005, pp 94-128.

PARK, R. A cidade: sugestões para a investigação do comportamento humano no meio urbano. In: VELHO, O. G. O Fenômeno Urbano. Rio de Janeiro: Zahar Editores, 1979, pp 26-113.

PATARRA, Neide L. FERNANDES, Duval. Brasil: país de imigração? RILP Revista Internacional de Lingua Portuguesa. Lisboa, III série, № 24, p. 65-96, 2011. RODRIGUES, Donizete. O Evangélico Imigrante: o pentecostalismo brasileiro salvando a América. São Paulo: Fonte Editora, 2016.

ROMIZI, Francesco. Religião, migrações e cultura, imagens da fé. Revista Mediações. Londrina, v. 12, no 18, p. 1-10, jan. jun. 2016.

\section{Fontes eletrônicas:}

Igreja Evangélica Holiness do Brasil: http://www.holiness.org.br/holiness/ - acesso em 09/08/2014 as $21 \mathrm{hrs} 33 \mathrm{~min}$.

Igreja Evangélica Holiness de Curitiba: http://www.holinesscwb.com/ - acesso em 09/08/2014 21hrs47min.

Igreja Evangélica Holiness de Londrina: http://holinesslondrina.wordpress.com/ acesso em 09/08/2014 22hrs03min..

Recebido: 06/10/2016

Received: $10 / 06 / 2016$

Aprovado: 01/11/2016

Approved: 11/01/2016 